\title{
Systemic inflammatory response syndrome and long-term outcome after intracerebral hemorrhage
}

\author{
Manuel Hagen, MD, Jochen A. Sembill, MD, Maximilian I. Sprügel, MD, Stefan T. Gerner, MD, \\ Dominik Madžar, MD, Hannes Lücking, MD, Philip Hölter, MD, Stefan Schwab, MD, Hagen B. Huttner, MD, PhD, \\ and Joji B. Kuramatsu, MD
}

Neurol Neuroimmunol Neuroinflamm 2019;6:e588. doi:10.1212/NXI.0000000000000588

\section{Abstract}

\section{Objective}

To investigate whether the systemic inflammatory response syndrome (SIRS) without infection as surrogate of a systemic immune response is associated with poor long-term functional outcome in patients with spontaneous intracerebral hemorrhage (ICH).

\section{Methods}

We analyzed consecutive patients with spontaneous ICH from our prospective cohort study (2018-2015). SIRS was defined according to standard criteria: i.e., 2 or more of the following parameters during hospitalization: body temperature $<36^{\circ} \mathrm{C}$ or $>38^{\circ} \mathrm{C}$, respiratory rate $>20$ per minute, heart rate $>90$ per minute, or white blood cell count $<4,000 / \mu \mathrm{L}$ or $>12,000 / \mu \mathrm{L}$ in the absence of infection. The primary outcome consisted of the modified Rankin Scale (mRS) at 3 and 12 months investigated by adjusted ordinal shift analyses. Bias and confounding were addressed by propensity score matching and multivariable regression models.

\section{Results}

Of 780 patients with ICH, 21.8\% $(\mathrm{n}=170)$ developed SIRS during hospitalization. Patients with SIRS showed more severe ICH compared with those without; i.e., larger ICH volumes (18.3 $\mathrm{cm}^{3}$, interquartile range [IQR $\left.4.6-47.2 \mathrm{~cm}^{3}\right]$ vs $7.4 \mathrm{~cm}^{3}$, IQR $\left.\left[2.4-18.6 \mathrm{~cm}^{3}\right] ; p<0.01\right)$, increased intraventricular hemorrhage $(57.6 \%, \mathrm{n}=98 / 170$ vs $24.8 \%, \mathrm{n}=79 / 319 ; p<0.01)$, and poorer neurologic admission status (NIH Stroke Scale score 16, IQR [7-30] vs 6, IQR [3-12]; $p<0.01)$. ICH severity-adjusted analyses revealed an independent association of SIRS with poorer functional outcome after 3 (OR 1.80, 95\% CI [1.08-3.00]; $p=0.025$ ) and 12 months (OR 1.76, 95\% CI [1.04-2.96]; $p=0.034$ ). Increased ICH volumes on follow-up imaging (OR $1.38,95 \%$ CI $[1.01-1.89] ; p=0.05$ ) and previous liver dysfunction (OR 3.01, 95\% CI [1.03-10.19]; $p=0.04)$ were associated with SIRS.

\section{Conclusions}

In patients with ICH, we identified SIRS to be predictive of poorer long-term functional outcome over the entire range of $\mathrm{mRS}$ estimates. Clinically relevant associations with SIRS were documented for previous liver dysfunction and hematoma enlargement.

\author{
Correspondence \\ Dr. Kuramatsu \\ joji.kuramatsu@uk-erlangen.de
}




\section{Glossary}

ERICH = Ethnic/Racial Variations of Intracerebral Hemorrhage; ICH = intracerebral hemorrhage; IQR = interquartile range; IVH = intraventricular hemorrhage; $\mathbf{m R S}$ = modified Rankin Scale; NIHSS = NIH Stroke Scale; PS = propensity score; SIRS = systemic inflammatory response syndrome.

Intracerebral hemorrhage ( $\mathrm{ICH})$ remains a significant cause of morbidity and mortality throughout the world, ${ }^{1}$ especially complications such as post-ICH infections during hospitalization contribute to disability and death. ${ }^{1}$ However, limited evidence exists regarding the influence of noninfectious systemic inflammation. ${ }^{2}$ Experimental studies suggest that $\mathrm{ICH}$ induces a cytokine-driven acute-phase inflammation, which may lead to secondary brain damage and systemic inflammatory response syndrome (SIRS). ${ }^{3}$

SIRS is frequently observed in patients with vascular diseases. In ICH, approximately $20 \%$ of patients develop SIRS during hospital stay, ${ }^{2}$ and a correlation between SIRS and stroke severity has been suggested. ${ }^{4}$ Recent stroke research has focused on systemic and local inflammatory responses as novel therapeutic target (NCT03338998), ${ }^{3,5}$ yet the association of SIRS with functional long-term outcomes after ICH remains undetermined. The present study aimed at investigating associations of SIRS with long-term functional outcome and contributing factors after $\mathrm{ICH}$.

\section{Methods}

\section{Patient selection}

We retrospectively analyzed all consecutive spontaneous patients with ICH $(\mathrm{n}=780)$ presenting to a tertiary care center in Germany from 2008 to 2015. We excluded secondary ICH etiologies such as trauma, arteriovenous malformation, aneurysms, tumor, acute thrombolysis, or coagulopathies. Our aim was to compare patients with noninfectious SIRS with a control group of patients without a systemic inflammatory reaction, all receiving full medical support, to investigate its associations with functional outcomes. The presence of SIRS (defined according to standard criteria $[\geq 2]$ simultaneously present over a 24 -hour period evaluated at hourly recordings: temperature $>38^{\circ} \mathrm{C}\left[100.4^{\circ} \mathrm{F}\right]$ or $<36^{\circ} \mathrm{C}\left[96.8^{\circ} \mathrm{F}\right]$, heart rate $>90$ beats per minute, respiratory rate $>20$ breaths per minute or arterial carbon dioxide tension $\mathrm{PaCO}_{2}<32 \mathrm{~mm} \mathrm{Hg}$, not scored in fully assisted mechanical ventilation, and white blood cell count $>12,000 / \mu \mathrm{L}$ or $<4,000 / \mu \mathrm{L}$ ) was evaluated during the entire hospital stay. Therefore, we excluded a total of 291 patients $(37.3 \%)$ with validated infections; i.e., sepsis, diagnosed according to standard diagnostic criteria; types of infections included pneumonia $(n=210 ; 72.2 \%)$, urinary tract infection $(\mathrm{n}=33 ; 11.3 \%)$, bloodstream infection $(\mathrm{n}=30 ; 10.3 \%)$, and CNS infection $(\mathrm{n}=18 ; 6.2 \%) .{ }^{6-8}$ Furthermore, 59 patients were excluded with early care limitations representing comfort care measures implemented within the first 24 hours after hospital admission leading to a total cohort of 430 patients (figure 1).

\section{Standard protocol approvals, registrations, and patient consents}

The study was approved by the ethics committee, and informed consent was obtained from all individual participants or legal representatives. Data were retrieved from our prospective institutional ICH cohort study (NCT03183167).

\section{Acquisition of demographic, clinical, and laboratory parameters}

Demographic and clinical data were retrieved from our prospective database. ${ }^{7}$ The presence of liver dysfunction was evaluated according to a common model for hemorrhagic risk assessment (HAS-BLED Score: Hypertension, Abnormal renal/liver function, Stroke, Bleeding history or predisposition, Labile international normalized ratio, Elderly [ $>65$ years], Drugs/alcohol concomitantly) defined as serum bilirubin $>2$ times upper limit with transaminases/alkaline phosphatase elevation $>3$ times upper normal limit on admission. ${ }^{9}$

All patients were comprehensively screened to identify clinical signs or evident infections to exclude sepsis. Infection screening was corroborated by medical chart, physicians' letters, laboratory, microbiological, radiologic, and institutional database review. Neuroradiologic parameters were evaluated using all available cranial CT and MRI, and hematoma location and intraventricular hemorrhage (IVH) were assessed as previously described. ${ }^{7} \mathrm{ICH}$ volume was calculated using validated methodology, ${ }^{10}$ and hematoma enlargement was scored if ICH volume on follow-up imaging was greater (33\%). ${ }^{11}$ Functional outcome was evaluated using the modified Rankin Scale (mRS) at 3 and 12 months, which was assessed by a standardized mailed questionnaire or semistructured telephone interview. ${ }^{7}$ Primary outcome analyses comprised functional status at 3 and 12 months (using the fullrange of the $\mathrm{mRS}$ ) analyzed according to SIRS status.

\section{Statistical analysis}

Data are presented as mean \pm SD for normally distributed continuous variables and median and interquartile range (IQR) for non-normally distributed continuous variables. All tests were 2 sided, and the significance level was set at $\alpha=0.05$. The Kolmogorov-Smirnov test was used to determine distribution of the data. Normally distributed data were compared using the Student $t$ test. For non-normally distributed continuous variables, we used the Mann-Whitney $U$ test (Control vs SIRS) and Kruskal-Wallis H test (Control vs SIRS vs Sepsis). Frequency distribution of categorized variables was compared using the Pearson $\chi^{2}$ test or the Fisher exact test, respectively, the 


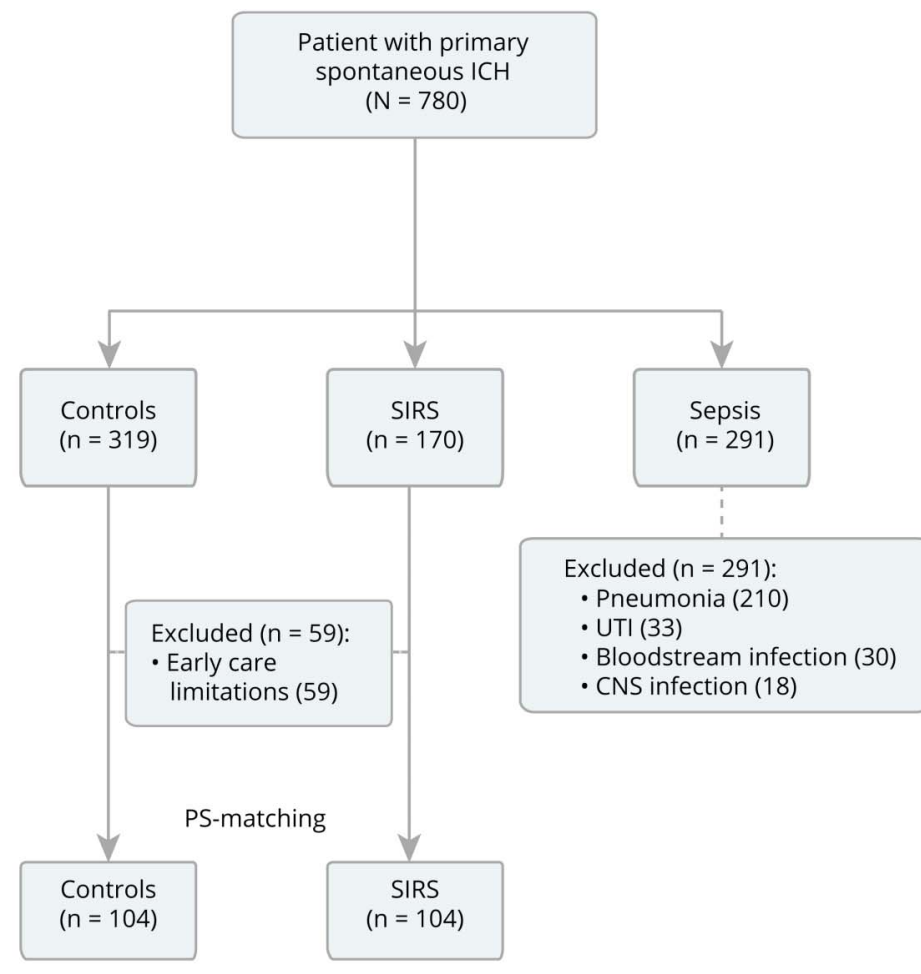

All consecutive primary spontaneous patients with $\mathrm{ICH}(\mathrm{n}=$ 780) treated during 2008-2015 were analyzed from our prospective institutional ICH cohort study (NCT03183167). We excluded 291 patients (37.3\%) with validated infections to patients with noninfectious SIRS to patients without; types of infections: pneumonia $(n=210 ; 72.2 \%)$ UTI $(n=33$; $11.3 \%)$, bloodstream infection $(n=30 ; 10.3 \%)$, and CNS infection $(n=18 ; 6.2 \%)$. Furthermore, 59 patients with $E C L s$, i.e., comfort care measures implemented within the first 24 hours after hospital admission were excluded, leading to a total cohort of 430 patients. $E C L=$ early care limitation; $\mathrm{ICH}=$ intracerebral hemorrhage; $\mathrm{mRS}=$ modified Rankin Primary outcome-shift-analyses of $\mathrm{mRS}$ at 3 and 12 months Secondary outcome-independent associations of SIRS Scale; PS = propensity score; SIRS = systemic inflammatory response syndrome; UTI = urinary tract infection.

Freeman-Halton extension of the Fisher exact test for trichotomous group comparisons. Bonferroni correction was performed to counteract accumulation of type 1 errors. To address bias and confounding, we performed propensity score (PS) matching using a parallel, balanced, 1:1 ratio nearest-neighbor approach with a caliper of 0.2 . We matched for parameters showing intergroup differences $(p<0.05)$ such as age, sex, NIH Stroke Scale (NIHSS) score, ICH volume, IVH, and length of hospital stay. Outcome analysis was calculated using the PSmatched cohort further controlled by multivariably adjusted ordinal shift analysis for age, ICH volume, NIHSS score on admission, IVH, and admission ward type (stroke unit or neurointensive care unit). Subanalyses constituted factors associated with SIRS using binary multivariable logistic regression models. Statistical analyses were performed using IBM SPSS Statistics 21.0 (spss.com) and R version 2.12.0 (r-project.corg).

\section{Data availability}

Anonymized data may be shared with qualified investigators upon request, depending on the terms of our regulatory approvals and institutional policy.

\section{Results}

Of 780 consecutive patients with ICH, $21.8 \%(n=170 / 780)$ developed noninfectious SIRS and 37.3\% $(n=291 / 780)$ developed sepsis during hospitalization (table 1); for infectious etiologies, see figure 1). Patients with SIRS compared with controls, i.e., patients who did not meet the SIRS criteria during the hospital stay (non-SIRS/non-Sepsis) showed significantly greater stroke severity (NIHSS score: 16, IQR [7-30] vs 6, IQR [3-12]; $p<0.01$; Glasgow Coma Scale score: 11, IQR [3-14] vs 15 , IQR [13-15]; $p<0.01)$ and less favorable ICH characteristics (ICH volume: $18.3 \mathrm{~cm}^{3}$, IQR [4.6-47.2] vs $7.4 \mathrm{~cm}^{3}$, IQR [2.4-18.6]; $p<0.01$; IVH: $57.6 \%, \mathrm{n}=98 / 170$ vs $24.8 \%, \mathrm{n}=79$ / 319; $p<0.01$; hematoma enlargement: $12.7 \%, \mathrm{n}=15 / 118$ vs $4.3 \%, \mathrm{n}=11 / 258 ; p<0.01)$. Unadjusted outcomes comparing SIRS vs controls (at hospital discharge: $\mathrm{mRS}$ score 5, IQR [4-6] vs 3, IQR [2-5]; at 3 months: $\mathrm{mRS}$ score 5, IQR [3-6] vs 3, IQR [2-4]; at 12 months: mRS score 6, IQR [3-6] vs 3, IQR [1-5]; all $p<0.01$ ) were all significantly in disfavor of patients with SIRS.

PS matching resulted in a well-balanced cohort of 104 patients with SIRS comparable to 104 controls. Validated outcome predictors in ICH showed no significant difference after matching for the comparison of patients with SIRS vs controls; age: 73 years, IQR ( $65-78$ years) vs 70 years, IQR (58-78 years); $p=0.24$; ICH volume: $10.5 \mathrm{~cm}^{3}$ IQR $\left(3.2-26.0 \mathrm{~cm}^{3}\right)$ vs $7.9 \mathrm{~cm}^{3}, \operatorname{IQR}\left(3.4-17.0 \mathrm{~cm}^{3}\right) ; p=0.32, \mathrm{IVH}: 41.3 \%, \mathrm{n}=43 / 104$ vs $34.6 \%, \mathrm{n}=36 / 104 ; p=0.32$; hematoma enlargement: $8.0 \%$, $\mathrm{n}=7 / 88$ vs $8.7 \%, \mathrm{n}=8 / 92 ; p=0.86$; NIHSS score: 10 , IQR (4-17) vs 8 , IQR (4-16); $p=0.59$ (table 2). 
Table 1 Baseline characteristics of patients with ICH with SIRS and sepsis

\begin{tabular}{|c|c|c|c|c|}
\hline & Control $(n=319)$ & $\operatorname{SIRS}(n=170)$ & Sepsis $(n=291)$ & $p$ Value \\
\hline Age, y (IQR) & $73(65-80)$ & $72(63-81)$ & $68(58-77)$ & 0.15 \\
\hline Female sex & $146(45.8 \%)$ & $90(52.9 \%)$ & $119(40.9 \%)$ & $0.04^{\mathrm{a}}$ \\
\hline \multicolumn{5}{|l|}{ Previous comorbidities } \\
\hline Hypertension & $267(83.7 \%)$ & $135(79.4 \%)$ & $243(83.5 \%)$ & 0.44 \\
\hline Diabetes mellitus & $96(30.1 \%)$ & $37(21.8 \%)$ & $71(24.4 \%)$ & 0.09 \\
\hline Dyslipidemia & $149(46.7 \%)$ & $60 / 168(35.7 \%)$ & $74(25.4 \%)$ & $0.02^{a}$ \\
\hline Previous ischemic stroke/TIA & $51(16.0 \%)$ & $33 / 169(19.5 \%)$ & $56(18.0 \%)$ & 0.48 \\
\hline Previous hemorrhagic stroke & $43(13.5 \%)$ & $11 / 169(6.5 \%)$ & $23(7.9 \%)$ & $0.03^{a}$ \\
\hline Congestive heart failure & $33(10.3 \%)$ & $17(10.0 \%)$ & $33(11.3 \%)$ & 0.90 \\
\hline Abnormal kidney function & $26(8.2 \%)$ & $16(9.4 \%)$ & $42(14.4 \%)$ & $0.04^{\mathrm{a}}$ \\
\hline Abnormal liver function & $14(4.4 \%)$ & $16(9.4 \%)$ & $25(8.6 \%)$ & $0.05^{a}$ \\
\hline Prestroke mRS score (IQR) & $0(0-2)$ & $1(0-2)$ & $1(0-2)$ & 0.78 \\
\hline \multicolumn{5}{|l|}{ Admission status } \\
\hline GCS (IQR) & $15(13-15)$ & $11(3-14)$ & $10(3-13)$ & $<0.01$ \\
\hline NIHSS score (IQR) & $6(3-12)$ & $16(7-30)$ & $19(12-32)$ & $<0.01$ \\
\hline \multicolumn{5}{|l|}{ Imaging } \\
\hline Deep & $127(39.8 \%)$ & $71(41.8 \%)$ & $165(56.7 \%)$ & $<0.01$ \\
\hline Lobar & $164(51.4 \%)$ & $79(46.5 \%)$ & $88(30.2 \%)$ & $<0.01$ \\
\hline Infratentorial & $28(8.8 \%)$ & $20(11.8 \%)$ & $38(13.1 \%)$ & $0.02^{\mathrm{a}}$ \\
\hline ICH volume, $\mathrm{cm}^{3}$ (IQR) & $7.4(2.4-18.6)$ & $18.3(4.6-47.2)$ & $19.2(9.0-45.0)$ & $<0.01$ \\
\hline IVH & $79(24.8 \%)$ & $98(57.6 \%)$ & $208(71.5 \%)$ & $<0.01$ \\
\hline Hematoma enlargement $^{b}$ & $11 / 258(4.3 \%)$ & $15 / 118(12.7 \%)$ & $28 / 267(10.5 \%)$ & $<0.01$ \\
\hline \multicolumn{5}{|l|}{ Outcome } \\
\hline Death at discharge & $25(7.8 \%)$ & $69(40.6 \%)$ & $52(17.9 \%)$ & $<0.01$ \\
\hline mRS score at discharge (IQR) & $3(2-5)$ & $5(4-6)$ & $5(5-5)$ & $<0.01$ \\
\hline Death 3 months & $43(13.5 \%)$ & $81 / 170(47.6 \%)$ & $95(32.6 \%)$ & $<0.01$ \\
\hline mRS score 3 months (IQR) & $3(2-4)$ & $5(3-6)$ & $5(4-6)$ & $<0.01$ \\
\hline Death 12 months & $61(19.1 \%)$ & $90(52.9 \%)$ & $130(44.7 \%)$ & $<0.01$ \\
\hline mRS score 12 months (IQR) & $3(1-5)$ & $6(3-6)$ & $5(4-6)$ & $<0.01$ \\
\hline ECLs & $16(5.0 \%)$ & $43(25.3 \%)$ & $17(5.8 \%)$ & $<0.01$ \\
\hline LOS (IQR) & $7.5(5.5-11.6)$ & $6.2(2.1-11.2)$ & $18.0(12.0-24.5)$ & $<0.01$ \\
\hline
\end{tabular}

Abbreviations: $\mathrm{ECL}=$ early care limitation; GCS = Glasgow Coma Scale; ICH = intracerebral hemorrhage; IQR = interquartile range 25th-75th percentile; IVH = intraventricular hemorrhage; LOS = length of hospital stay; mRS = modified Rankin Scale; NIHSS = NIH Stroke Scale; SIRS = systemic inflammatory response syndrome.

Multiple comparisons were corrected by the Bonferroni method.

${ }^{a}$ Not significant after Bonferroni correction.

b Hematoma enlargement $>33 \%$ in follow-up imagine.

For primary outcome analysis (figure 2), we used the PSmatched cohort, which was further multivariably adjusted for ICH severity. Noninfectious SIRS was independently associated with poorer functional status at 3 and 12 months (mRS at 3 months: $\mathrm{OR}=1.80,95 \% \mathrm{CI}[1.08-3.00] ; p=0.025$; mRS at 12 months: $\mathrm{OR}=1.76,95 \% \mathrm{CI}[1.04-2.96] ; p=0.034)$. Secondary outcome analyses of parameters potentially predictive of SIRS (table 3) showed independent associations of 
Table 2 Baseline characteristics after propensity score matching

\begin{tabular}{|c|c|c|c|}
\hline & Control $(n=104)$ & SIRS $(n=104)$ & $p$ Value \\
\hline Age, y (IQR) & 70 (58-78) & $73(65-78)$ & 0.24 \\
\hline Female sex & $47(45.2 \%)$ & $59(56.7 \%)$ & 0.10 \\
\hline Prestroke mRS score (IQR) & $0(0-2)$ & $0(0-2)$ & 0.85 \\
\hline \multicolumn{4}{|l|}{ Imaging } \\
\hline ICH volume, $\mathrm{cm}^{3}$ (IQR) & $7.9(3.4-17.0)$ & $10.5(3.2-26.0)$ & 0.32 \\
\hline IVH & 36 (34.6\%) & 43 (41.3\%) & 0.32 \\
\hline Hematoma enlargement (>33\%) & $7 / 88(8.0 \%)$ & $8 / 92(8.7 \%)$ & 0.86 \\
\hline \multicolumn{4}{|l|}{ Admission status } \\
\hline GCS score (IQR) & $14(12-15)$ & $13(11-15)$ & 0.14 \\
\hline NIHSS score (IQR) & $8(4-16)$ & $10(4-17)$ & 0.59 \\
\hline LOS (IQR) & $8.2(5.3-12.4)$ & $9.4(6.0-13.2)$ & 0.22 \\
\hline
\end{tabular}

Abbreviations: GCS = Glasgow Coma Scale; ICH = intracerebral hemorrhage; IQR = interquartile range 25th-75th percentile; IVH = intraventricular hemorrhage; LOS = length of hospital stay; mRS = modified Rankin Scale; NIHSS = NIH Stroke Scale; SIRS = systemic inflammatory response syndrome.

SIRS with larger hematoma volumes $(\mathrm{OR}=1.38,95 \% \mathrm{CI}$ $[1.01-1.89] ; p=0.05)$ and previous liver dysfunction $(\mathrm{OR}=$ $3.01,95 \%$ CI $[1.03-10.19] ; p=0.04)$.

\section{Discussion}

To our knowledge, this is the first study to investigate the association of noninfectious SIRS with long-term functional outcome after ICH. We observed a high prevalence of SIRS (22\%) and detected independent associations with poorer functional outcome over the entire range of mRS estimates. Factors potentially contributing to SIRS were preexisting liver dysfunction and hematoma enlargement, although cause and effect remain to be established.

Associations between in-hospital SIRS and poorer outcome at discharge were previously reported by Boehme et al. ${ }^{2}$ evaluating 249 patients with ICH from a single center study. Contradictory findings were reported from the large prospective multicenter $(n=2,441)$ Ethnic/Racial Variations of Intracerebral Hemorrhage (ERICH) cohort, which did not confirm this association between SIRS and poorer outcomes at discharge and after 3 months. These discrepant findings may emphasize the importance of the SIRS evaluation period as the first confirmatory study evaluated SIRS similarly to the present study over the entire hospital stay, whereas for the ERICH-cohort, SIRS was only assessed at a single time point, i.e., hospital admission. Another study based on a large randomized data set from the Intensive Blood Pressure Reduction in Acute Cerebral Haemorrhage Trials I and II investigated associations of admission heart rate with outcomes, showing that an elevation above 84 beats per minute was negatively affecting short-term outcome. ${ }^{12}$ However, for the present study, we evaluated SIRS criteria over a 24-hour period during the entire hospital stay capturing all patients with initial, sustained, or delayed systemic inflammatory response. Importantly, single time point assessment, only at hospital admission, may theoretically be prone to confounding aspects such as volume status (dehydration), anemia, arrhythmia, comorbidity, and body temperature influenced by timing from symptom onset to admission. Furthermore, diagnosis and detection of true infections may be compromised by treatment intensity, as those severely affected patients (older age, large $\mathrm{ICH}$, and poor neurologic status) with an additive picture of septic shock may potentially receive earlier care limitations impeding accurate SIRS classification (noninfectious vs infectious).

We observed a high prevalence of SIRS (22\%) during hospital stay, and SIRS-positive patients had more severe ICH with significantly larger ICH volumes, more $\mathrm{IVH}$, and hence poorer neurologic status. ${ }^{2,13}$ This possibly suggests a correlation between stroke severity and SIRS mechanistically encompassing a stroke-induced systemic inflammation process, which has been supported by increased serum cytokine concentrations found in larger ICH volumes. ${ }^{3}$ In $\mathrm{ICH}$, inflammation begins immediately after hematoma formation and early reactions are driven by local microglia activation, release of cytokines, and chemokines, which are subsequently released into systemic circulation. Nevertheless, it has been hypothesized that novel immunotherapeutic approaches (NCT03338998) in stroke mainly focus on local phenomena inducing secondary brain injury. ${ }^{14}$ Our data importantly suggest that systemic inflammation itself is an independent predictor of outcome, thereby representing a potential treatment target of immunomodulation with greater effect size than previously anticipated. Furthermore, we identified previous liver dysfunction and larger ICH volumes on follow-up imaging to be associated with SIRS. Relations between liver 
B. 12 months
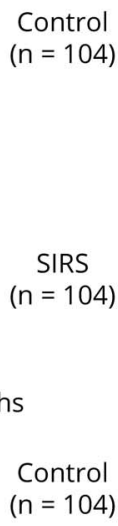

SIRS

$(n=104)$

$(n=104)$

SIRS

$(n=104)$

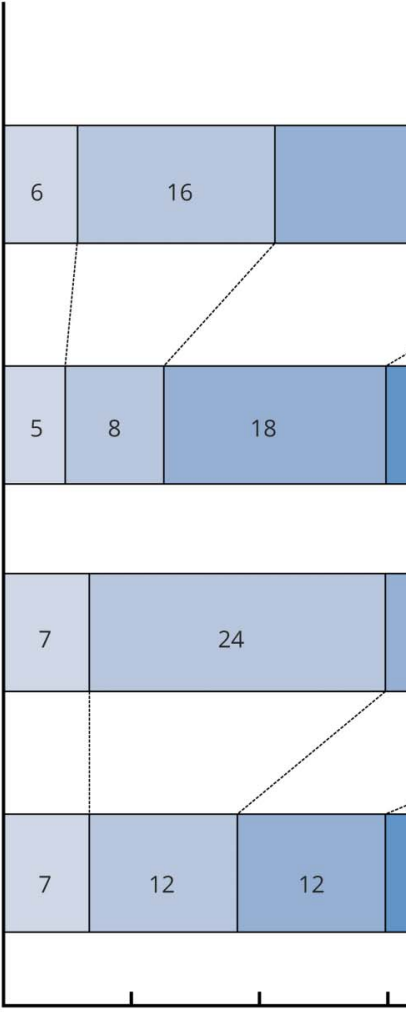

20
26
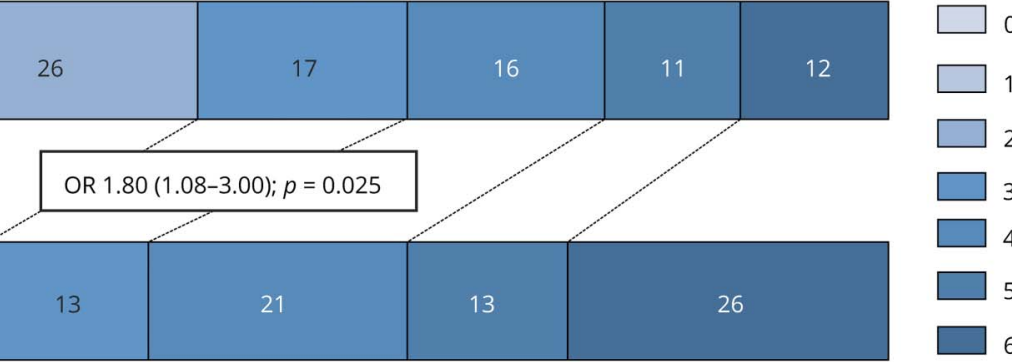

0
2

Comparison of the mRS score between patients with ICH with and without SIRS presented at 3 (A) and 12 months (B). Analyses were calculated using the propensity score-matched cohort multivariably adjusted for age, ICH volume, NIHSS score on admission, intraventricular hemorrhage, and admission ward type. ICH = intracerebral hemorrhage; mRS = modified Rankin Scale; SIRS = systemic inflammatory response syndrome.

dysfunction and systemic inflammation were previously reported, i.e., in patients with cirrhosis, 39\% met the SIRS criteria and were showing poorer outcome. ${ }^{15}$ In line, we report an increased susceptibility for SIRS development in patients with $\mathrm{ICH}$ with previous liver dysfunction. However, interactions between these 2 findings (liver dysfunction, coagulopathy, and larger ICH volumes) remain to be determined.

Our study has several limitations, mainly the retrospective nature and monocentric design. Patients were routinely screened for infections according to internal standards; however, a prospective screening methodology was not applied, influencing the temporal resolution of SIRS-associated factors to determine causality. According to our institutional protocol, prophylactic antibiotics were not recommended, although antibiotic use was applied at the discretion of the treating physicians, potentially introducing treatment variability and possibly influencing detection of infectious causes. Institutionally, temperature management comprised treatment at body core temperatures $\geq 37.5^{\circ} \mathrm{C}$ consisting of an escalating regime, i.e., antipyretic medications, cooled infusions, body surface cooling methods, and ultimately IV cooling catheters, which did not show significant differences between patients with SIRS and controls. Furthermore, sensitivity analyses of catecholamine use within the present cohort did not result in a greater likelihood of type I errors for SIRS scoring (data not shown). Although rigorous statistical means to control for confounding have been applied, residual bias cannot be fully excluded.

In patients with $\mathrm{ICH}$, we identified SIRS to be independently predictive of poorer long-term functional outcome over the entire range of $\mathrm{mRS}$ estimates. Clinically relevant associations with SIRS were documented for previous liver dysfunction and hematoma enlargement.

\section{Study funding}

Supported by a research grant (FWN/Zo-Hutt/2011) from the Johannes and Frieda Marohn Foundation, University of Erlangen, Germany.

\section{Disclosure}

The authors report no disclosures. Go to Neurology.org/NN for full disclosures. 
Table 3 Exploratory analyses of parameters associated with SIRS

\begin{tabular}{|c|c|c|c|c|}
\hline \multirow[b]{2}{*}{ Total patients $(n=208)$} & \multicolumn{2}{|c|}{ Univariable regression } & \multicolumn{2}{|c|}{ Multivariable regression } \\
\hline & OR $(95 \% \mathrm{CI})$ & $p$ Value & OR $(95 \% \mathrm{Cl})$ & $p$ Value \\
\hline Age, y & $1.01(0.99-1.04)$ & 0.20 & & \\
\hline Female sex & $1.59(0.92-2.75)$ & 0.10 & $1.67(0.90-3.03)$ & 0.11 \\
\hline \multicolumn{5}{|l|}{ Previous comorbidities } \\
\hline Hypertension & $1.07(0.53-2.17)$ & 0.86 & & \\
\hline Diabetes mellitus & $0.62(0.25-1.49)$ & 0.28 & & \\
\hline Dyslipidemia & $0.96(0.56-1.66)$ & 0.89 & & \\
\hline Previous ischemic stroke/TIA & $1.75(0.84-3.64)$ & 0.14 & & \\
\hline Previous hemorrhagic stroke & $0.62(0.25-1.49)$ & 0.28 & & \\
\hline Congestive heart failure & $1.24(0.49-3.12)$ & 0.66 & & \\
\hline Abnormal kidney function & $1.14(0.42-3.07)$ & 0.80 & & \\
\hline Abnormal liver function & $2.83(0.97-8.25)$ & 0.06 & $3.01(1.03-10.19)$ & 0.04 \\
\hline Premorbid mRS score & $1.01(0.80-1.27)$ & 0.91 & & \\
\hline \multicolumn{5}{|l|}{ Imaging } \\
\hline Deep & $0.59(0.34-1.04)$ & 0.07 & & \\
\hline Lobar & $1.65(0.96-2.86)$ & 0.07 & $1.35(0.72-2.55)$ & 0.74 \\
\hline Infratentorial & $1.00(0.40-2.51)$ & 1.00 & & \\
\hline ICH volume & $1.01(0.99-1.02)$ & 0.34 & & \\
\hline ICH volume follow-up ${ }^{a}$ & $1.45(1.07-1.96)$ & 0.02 & $1.38(1.01-1.89)$ & 0.05 \\
\hline IVH & $1.33(0.76-2.34)$ & 0.32 & & \\
\hline \multicolumn{5}{|l|}{ Admission status } \\
\hline Temperature & $1.11(0.63-1.95)$ & 0.71 & & \\
\hline GCS score & $0.96(0.88-1.05)$ & 0.34 & & \\
\hline NIHSS score & $1.01(0.98-1.04)$ & 0.61 & & \\
\hline
\end{tabular}

Abbreviations: GCS = Glasgow Coma Scale; ICH = intracerebral hemorrhage; IVH = intraventricular hemorrhage; $\mathrm{mRS}=$ modified Rankin Scale; $\mathrm{NIHSS}=\mathrm{NIH}$ Stroke Scale; SIRS = systemic inflammatory response syndrome.

Multivariable regression analysis was computed to delineate contributing factors associated with SIRS development for the PS-matched cohort of patients with $\mathrm{ICH}$. Parameters with $p$ value $\leq 0.10$ in univariate analysis were included.

a ICH volume on follow-up was categorized as follows: $<15 \mathrm{~cm}^{3}, 15-30 \mathrm{~cm}^{3}, 30-45 \mathrm{~cm}^{3}, 45-60 \mathrm{~cm}^{3}$, and $>60 \mathrm{~cm}^{3}$.

\section{Publication history}

Received by Neurology: Neuroimmunology \& Neuroinflammation February 21, 2019. Accepted in final form May 2, 2019.

\section{Appendix Authors}

\begin{tabular}{|c|c|c|c|}
\hline Name & Location & Role & Contributions \\
\hline $\begin{array}{l}\text { Manuel } \\
\text { Hagen, MD }\end{array}$ & $\begin{array}{l}\text { University of } \\
\text { Erlangen- } \\
\text { Nuremberg, } \\
\text { Germany }\end{array}$ & First author & $\begin{array}{l}\text { Designed the study; } \\
\text { analyzed the data; } \\
\text { and drafted the } \\
\text { manuscript for } \\
\text { intellectual content }\end{array}$ \\
\hline $\begin{array}{l}\text { Jochen A. } \\
\text { Sembill, MD }\end{array}$ & $\begin{array}{l}\text { University of } \\
\text { Erlangen- } \\
\text { Nuremberg, } \\
\text { Germany }\end{array}$ & Author & $\begin{array}{l}\text { Major role in the } \\
\text { acquisition of data } \\
\text { and analyzed the } \\
\text { data }\end{array}$ \\
\hline
\end{tabular}

Appendix (continued)

\begin{tabular}{llll}
\hline Name & Location & Role & Contributions \\
\hline $\begin{array}{l}\text { Maximilian } \\
\text { I. Sprügel, } \\
\text { MD }\end{array}$ & $\begin{array}{l}\text { University of } \\
\text { Erlangen- } \\
\text { Nuremberg, } \\
\text { Germany }\end{array}$ & Author & $\begin{array}{l}\text { Major role in the } \\
\text { acquisition of data } \\
\text { and analyzed the } \\
\text { data }\end{array}$ \\
\hline $\begin{array}{l}\text { Stefan T. } \\
\text { Gerner, MD }\end{array}$ & $\begin{array}{l}\text { University of } \\
\text { Erlangen- } \\
\text { Nuremberg, } \\
\text { Germany }\end{array}$ & Author & $\begin{array}{l}\text { Major role in the } \\
\text { acquisition of data }\end{array}$ \\
\hline $\begin{array}{l}\text { Dominik } \\
\text { Madžar, MD }\end{array}$ & $\begin{array}{l}\text { University of } \\
\text { Erlangen- } \\
\text { Nuremberg, } \\
\text { Germany }\end{array}$ & Author & Major role in the \\
& & & \\
& & &
\end{tabular}


Appendix (continued)

\begin{tabular}{|c|c|c|c|}
\hline Name & Location & Role & Contributions \\
\hline $\begin{array}{l}\text { Hannes } \\
\text { Lücking, MD }\end{array}$ & $\begin{array}{l}\text { University of } \\
\text { Erlangen- } \\
\text { Nuremberg, } \\
\text { Germany }\end{array}$ & Author & $\begin{array}{l}\text { Major role in the } \\
\text { acquisition of data }\end{array}$ \\
\hline $\begin{array}{l}\text { Philip } \\
\text { Hölter, MD }\end{array}$ & $\begin{array}{l}\text { University of } \\
\text { Erlangen- } \\
\text { Nuremberg, } \\
\text { Germany }\end{array}$ & Author & $\begin{array}{l}\text { Major role in the } \\
\text { acquisition of data }\end{array}$ \\
\hline $\begin{array}{l}\text { Stefan } \\
\text { Schwab, MD }\end{array}$ & $\begin{array}{l}\text { University of } \\
\text { Erlangen- } \\
\text { Nuremberg, } \\
\text { Germany }\end{array}$ & Author & $\begin{array}{l}\text { Interpreted the data } \\
\text { and revised the } \\
\text { manuscript for } \\
\text { intellectual content }\end{array}$ \\
\hline $\begin{array}{l}\text { Hagen B. } \\
\text { Huttner, } \\
\text { MD, PhD }\end{array}$ & $\begin{array}{l}\text { University of } \\
\text { Erlangen- } \\
\text { Nuremberg, } \\
\text { Germany }\end{array}$ & Author & $\begin{array}{l}\text { Interpreted the data } \\
\text { and revised the } \\
\text { manuscript for } \\
\text { intellectual content }\end{array}$ \\
\hline $\begin{array}{l}\text { Joji B. } \\
\text { Kuramatsu, } \\
\text { MD }\end{array}$ & $\begin{array}{l}\text { University of } \\
\text { Erlangen- } \\
\text { Nuremberg, } \\
\text { Germany }\end{array}$ & $\begin{array}{l}\text { Corresponding } \\
\text { author }\end{array}$ & $\begin{array}{l}\text { Designed the study; } \\
\text { analyzed the data; } \\
\text { and drafted the } \\
\text { manuscript for } \\
\text { intellectual content }\end{array}$ \\
\hline
\end{tabular}

\section{References}

1. Hemphill JC III, Greenberg SM, Anderson CS, et al. Guidelines for the management of spontaneous intracerebral hemorrhage: a guideline for healthcare professionals from the American heart Association/American Stroke Association. Stroke 2015;46: 2032-2060.
2. Boehme AK, Hays AN, Kicielinski KP, et al. Systemic inflammatory response syndrome and outcomes in intracerebral hemorrhage. Neurocrit Care 2016;25: 133-140.

3. Fu Y, Liu Q, Anrather J, Shi FD. Immune interventions in stroke. Nat Rev Neurol 2015;11:524-535.

4. Boehme AK, Comeau ME, Langefeld CD, et al. Systemic inflammatory response syndrome, infection, and outcome in intracerebral hemorrhage. Neurol Neuroimmunol Neuroinflamm 2018;5:e428. doi: 10.1212/NXI.0000000000000428.

5. Fu Y, Hao J, Zhang N, et al. Fingolimod for the treatment of intracerebral hemorrhage: a 2-arm proof-of-concept study. JAMA Neurol 2014;71:1092-1101.

6. Sembill JA, Gerner ST, Volbers B, et al. Severity assessment in maximally treated ICH patients: the max-ICH score. Neurology 2017;89:423-431.

7. Sprugel MI, Kuramatsu JB, Gerner ST, et al. Antiplatelet therapy in primary spontaneous and oral anticoagulation-associated intracerebral hemorrhage. Stroke 2018; 49:2621-2629.

8. Levy MM, Fink MP, Marshall JC, et al. 2001 SCCM/ESICM/ACCP/ATS/SIS international sepsis definitions conference. Crit Care Med 2003;31: 1250-1256.

9. Pisters R, Lane DA, Nieuwlaat R, de Vos CB, Crijns HJ, Lip GY. A novel user-friendly score (HAS-BLED) to assess 1-year risk of major bleeding in patients with atrial fibrillation: the Euro Heart Survey. Chest 2010;138:1093-1100.

10. Huttner $\mathrm{HB}$, Steiner $\mathrm{T}, \mathrm{Hartmann} \mathrm{M}$, et al. Comparison of $\mathrm{ABC} / 2$ estimation technique to computer-assisted planimetric analysis in warfarin-related intracerebral parenchymal hemorrhage. Stroke 2006;37:404-408.

11. Brott T, Broderick J, Kothari R, et al. Early hemorrhage growth in patients with intracerebral hemorrhage. Stroke 1997;28:1-5.

12. Qiu M, Sato S, Zheng D, et al. Admission heart rate predicts poor outcomes in acute intracerebral hemorrhage: the intensive blood pressure reduction in acute cerebral hemorrhage trial studies. Stroke 2016;47:1479-1485.

13. Di Napoli M, Behrouz R, Topel $\mathrm{CH}$, et al. Hypoalbuminemia, systemic inflammatory response syndrome, and functional outcome in intracerebral hemorrhage. J Crit Care 2017;41:247-253.

14. Elkins J, Veltkamp R, Montaner J, et al. Safety and efficacy of natalizumab in patients with acute ischaemic stroke (ACTION): a randomised, placebo-controlled, doubleblind phase 2 trial. Lancet Neurol 2017;16:217-226.

15. Cazzaniga M, Dionigi E, Gobbo G, Fioretti A, Monti V, Salerno F. The systemic inflammatory response syndrome in cirrhotic patients: relationship with their inhospital outcome. J Hepatol 2009;51:475-482. 


\section{Neurology \\ Neuroimmunology \& Neuroinflammation}

\section{Systemic inflammatory response syndrome and long-term outcome after intracerebral hemorrhage \\ Manuel Hagen, Jochen A. Sembill, Maximilian I. Sprügel, et al. \\ Neurol Neuroimmunol Neuroinflamm 2019;6; \\ DOI 10.1212/NXI.0000000000000588}

This information is current as of July 1, 2019

\section{Updated Information \& \\ Services}

References

Citations

Subspecialty Collections

Permissions \& Licensing

Reprints including high resolution figures, can be found at:

http://nn.neurology.org/content/6/5/e588.full.html

This article cites 15 articles, 4 of which you can access for free at: http://nn.neurology.org/content/6/5/e588.full.html\#\#ref-list-1

This article has been cited by 2 HighWire-hosted articles: http://nn.neurology.org/content/6/5/e588.full.html\#\#otherarticles

This article, along with others on similar topics, appears in the following collection(s):

Intracerebral hemorrhage

http://nn.neurology.org//cgi/collection/intracerebral_hemorrhage Prognosis

http://nn.neurology.org//cgi/collection/prognosis

Information about reproducing this article in parts (figures,tables) or in its entirety can be found online at:

http://nn.neurology.org/misc/about.xhtml\#permissions

Information about ordering reprints can be found online:

http://nn.neurology.org/misc/addir.xhtml\#reprintsus

Neurol Neuroimmunol Neuroinflamm is an official journal of the American Academy of Neurology.

Published since April 2014, it is an open-access, online-only, continuous publication journal. Copyright

Copyright $\odot 2019$ The Author(s). Published by Wolters Kluwer Health, Inc. on behalf of the American

Academy of Neurology.. All rights reserved. Online ISSN: 2332-7812.

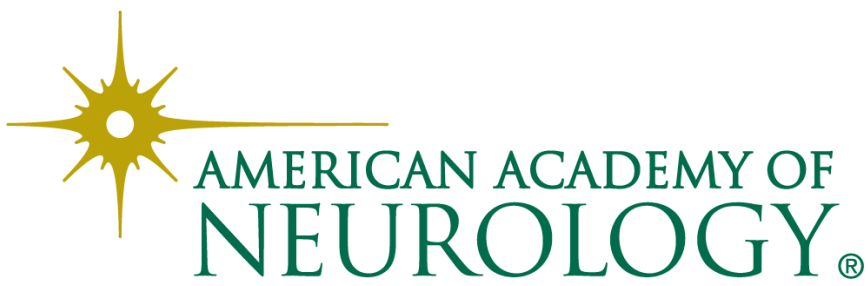

